\title{
Research on Enterprise Digital Innovation, Consumer Digital Technology Readiness and Purchase Intention
}

\author{
Xuge Song ${ }^{1 *}$ \\ ${ }^{1}$ Henan University, Business School, China
}

\begin{abstract}
With the development of digital technology, we have entered the digital age. Under the background of digital age, brands have to follow the trend of digitization. How to build and develop brands has become an important research. Most scholars research on brand building and development from the perspective of enterprises, while this research explores the impact of consumer technological readiness on purchase intentions in the digital context from the perspective of consumers. According to the findings of this study, consumers with high technological readiness hold an optimistic and innovative attitude towards digital technology, so they are willing to accept and try new products or services produced by the brand's application of digital technology, and increase their willingness to buy brands; for consumers with low technical readiness, they have doubts and distrust of digital technology and have low driving belief, and their purchase intention is reduced for new products produced by brand application of digital technology. Digital technology has a favorable impact on the economic growth of enterprises. The application of digital technology greatly improves the production efficiency of enterprises and saves energy consumption for enterprises. Therefore, the growth of digital economy also brings benefits to energy-saving economy.
\end{abstract}

\section{Introduction}

With the rapid development of digital technology, we are in a period of digital revolution. Digital transformation is reshaping the whole market segment and industry: communication and retail. And more and more other industries, such as health care, medicine, agriculture and manufacturing[1]. The application of digital technology by enterprises in various industries has improved the production and operation efficiency of enterprises, and the social digital economy has grown. The application of digital technology has led to the improvement of the efficiency of the whole society and the further improvement of energy-saving economy. The innovation of enterprises also needs to be combined with digitalization, therefore it is an inevitable trend for brands to transform with the help of digital technology. However, the concept of customer-centered brand building determines that customers' attitudes and cognitive ideas must be considered in the strategic transformation of brands. Digital technology plays an important role in the digital transformation and innovation of enterprises, which is very important to enterprises. However, with the development of digital technology, consumers' daily life and consumption patterns are also greatly affected, so it is also very important to look at digital technology from the consumer's point of view. Consumers' positive or negative attitude towards digital technology affects their consumption and use behavior.
At present, most scholars have studied the benefits of digital transformation and innovation for enterprises and the impact on consumers' daily lives. However, there is no discussion on consumers' attitude towards enterprises using new technologies to create new products or service innovations, and whether consumers' attitude towards digital technologies will affect their purchasing intentions. Therefore, this article explores the impact of customer technical readiness on brand purchase intention in the digital context. In other words, under the digital background, enterprise innovation is transformed by means of digital technology, and how will consumers' attitude towards digital technology affect the brand's purchase intention?

\section{Literature review}

\subsection{Digital innovation}

\subsubsection{Digital technology}

Digital technology constitutes the foundation of platform and digital environment innovation[2], which is one of the necessary conditions for digital transformation of enterprises and an important factor driving digital innovation of enterprises. David et al., (2010) showed that digitilization can be understood as the application of digital technology to a wider social and institutional environment[3]. Digital technology is one of the external driving forces leading to digital transformation. Since the

* Corresponding author: 2778339910@qq.com 
emergence of the World Wide Web and its worldwide adoption, more and more digital technologies (for example, broadband Internet, smart phones, Internet 2. 0, search engine optimization, cloud computing, voice recognition, online payment systems and cryptocurrency) emerge[4]. Digitalization creates a new way for companies to create added value in business. Modernization of enterprises through the combination of digital technology, physical resources and personal creativity is an important step in the transformation of innovative business, which may constitute a competitive advantage[5]. Based on the above, a brand's transformation in accordance with the digital trend can be understood as the brand's application of digital technology to its products or services, publicity, marketing and other production and operation processes. In addition, while companies provide consumers with various digital products and services, consumers are also affected by new forms of consumption related to these digital technologies[6].

\subsubsection{Enterprise digital innovation}

Yoo et al., (2010) define digital innovation as a new combination of digital and physical components and the production of new products[7]. Wang(2021) further points out that new combinations of digital and physical components can also generate new value creation processes or business models and define digital innovation as the adopter creating new products, processes or business models by information technology. For example, UAVs, 3D printing and sharing economies represent digital innovation in the form of products, processes and business models, respectively[8]. Digital background, the innovation team needs to use $5 \mathrm{G}$, the Internet of things, virtual reality and artificial intelligence to process digital technology output, need to be more agile and dynamic digital technology into the innovation process[9]. Most digital designs are still incomplete and in a changing state. The scale and scope of innovation can be expanded by various enterprises participating in innovation. The boundaries of digital innovation achievements are infinite and changeable, and products, platforms and services are unpredictable and dynamic[10].

According to the above literature review of digital technology and digital innovation, we find that digital technology is a necessary condition for enterprise digital innovation. Enterprises combine digital and physical components to form a new combination with digital technology to produce new products, value creation processes and business models. The boundaries of enterprise digital innovation achievements are infinite and changeable. Digital technology creates conditions for the development of enterprises, and the transformation and innovation of enterprises by using digital technology can improve the overall operational efficiency of production, transportation, publicity, etc. All of these look at digital technology from the perspective of enterprises. But what is digital technology from the perspective of consumers? Next, we will study consumers' attitudes towards digital technology.

\subsection{Technology Readiness}

Modern science and technology are developing rapidly. If consumers are not prepared for it, they will not be able to accept new technologies and new products or services produced by new technologies. Attitude is one of the basic concepts in consumer behavior research, technology Readiness is a consumer's attitude towards technology and a key factor for users to adopt new products and services. In the current research, the objects of interest are technology and technology-based products and services[11]. The American marketing scholar Parasuraman first proposed the concept of technical readiness. Technical readiness is described as the tendency of people to try and adopt new technologies. This tendency is influenced by both driving factors and inhibitors; driving factors and inhibitors are both It can be subdivided into four dimensions: optimism and innovation, discomfort and insecurity. Parasuraman (2000) defines optimism as a positive attitude towards technology and its results and benefits, while innovation is the first trend for consumers to accept and use new technologies[12]. Discomfort refers to the feeling that consumers are overwhelmed by technology and can't control it, while insecurity refers to consumers' distrust of technology, its results and its consequences.

Scholars' research on technology readiness mainly has two aspects. On the one hand, the research mainly regards technology readiness as an independent variable that directly affects consumers' belief in technology and technology adoption[13, 14]. On the other hand, some studies regard technical readiness as a moderating effect to verify the differences between different theoretical groups. For example, Borrero et al. (2014) divided the respondents into two groups (i. e., high TR and low TR) to compare the difference of the hypothetical relationship between the two groups[15]. However, as an individual feature, technical readiness can also be used to adjust the relationship between user motivation and behavioral intention[16, 17]. Existing studies seldom regard the overall technical readiness as a moderating factor, and examine its moderating effect on the relationship between technology-related beliefs and technology adoption[18].

The above is a review of the connotation of technology readiness. It can be seen that technology readiness represents the subjective attitude of consumers towards a certain technology. Whether consumers are willing to use a certain technology or accept new things produced by new technology is influenced by consumers' attitude towards the technology.

\subsection{Purchasing Intention}

The concept of purchase intention was first proposed by Aaker, pointing out that purchase intention is a subjective tendency related to products or brands[19]. Some scholars define purchase intention as the 
subjective probability and possibility that consumers are willing to buy a certain product or service, that is, the greater the purchase intention of consumers, the higher the probability of their purchase[20]. The ultimate goal of daily business and strategic management activities of enterprises is to meet the needs of consumers. Purchase intention is a leading indicator of consumer behavior and can be used as an important measurement indicator to predict consumer behavior. When consumers need to choose specific products or services, they will form purchase intention, and consumer attitude is an important factor affecting purchase intention[21]. Consumer's attitude is the emotional degree of approval or opposition to something. Individual's attitude to things affects their willingness to act and plays a major role in consumers' willingness to buy[22]. Purchase intention is an important factor to measure brand performance, which reflects the success of a brand in the market and aims to evaluate the strategic success of a brand[23]. Therefore, the purchase intention is an important factor to improve brand performance. The higher the purchase intention, the greater the possibility of consumers implementing purchase behavior. The real occurrence of purchase behavior will also increase the sales of enterprises and further promote the financial performance of enterprises. Therefore, it is very important to study the influence of consumers' attitude towards digital technology on their purchase intention.

\section{The influence of consumer's digital technology readiness on purchase intention}

From the above literature review of digital innovation, we can conclude that the necessary condition of digital innovation is digital technology. Under the digital background, all industries and enterprises are trying to catch up with the digital trend to avoid falling behind, but consumers' attitudes towards digital technology are seldom considered. Consumers' positive attitude towards brand will promote their purchase intention. On the contrary, consumers' negative attitude towards brand will reduce their purchase intention, which is also a part of enterprise performance (based on consumers). Therefore, it is very important to study the influence of consumers' digital technology readiness difference on purchase intention.

For new technologies and products or services produced by new technologies, consumers will have two opposite emotions, one is a positive attitude, the other is a negative attitude, and the sum of the positive and negative attitudes determines the consumer's The level of technical readiness is high or low. Although consumers' attitude towards technology is that positive and negative emotions are intertwined, one of them must be dominant in the end, and the final positive or negative dominant position varies from person to person. Drive (optimism and innovation) and restraint (discomfort and insecurity) together determine the propensity of consumers to use new technologies and technologybased products or services. When the consumer's attitude towards technology is positive, that is, optimistic and innovative, which surpasses the negative forces of discomfort and insecurity, the technological readiness is high; and when the consumer's attitude towards technology is positive, that is, optimistic. And perception of innovation, does not exceed the negative power of discomfort and insecurity, low technical readiness. Therefore, when consumers perceive brand digitization, their driving force is stronger than their inhibitory power, and their technical readiness is high; conversely, when consumers perceive brand digitization, their driving force is weaker than their inhibitory power, and their technical readiness is low. When technology is an indispensable part of the production and consumption of service products, technical preparation is obviously important. This is because people's personal characteristics will affect the individual's acceptance of new technologies[24]. It can be seen that it is very important for companies to consider consumer attitudes towards digital technology.

Technology readiness has a positive impact on purchase intention, which is not applicable to all consumers. As for the attitude towards digitalization and the increasing introduction of technology in daily life, active users take a positive view of this trend, thinking that all innovations are beneficial, while traditional users have a relatively neutral attitude towards this. They think that although this trend has a positive side, they will still be skeptical about what is happening. Therefore, different consumers have different levels of technical readiness, and their acceptance of new products or services is also different. Consumers with high level of technical readiness are more optimistic and confident about the products and services produced by new technologies, so they are willing to try new technology products and services and promote the formation of purchase intention. Therefore, consumers with high technical readiness have higher driving beliefs and an optimistic and innovative attitude towards digital technology, which makes them have more confidence in digital technology, so that they are willing to accept and try new products or services produced by the application of digital technology, and further promote their purchase willingness; However, if consumers with low technical readiness have low driving beliefs, consumers will have doubts and distrust on the application of digital technology adopted by brands and its results, which will lead to lower purchase intention.

As can be seen from the above, consumers' attitude towards digital technology positively affects consumers' purchase intention, and consumers are highly prepared for technology and increase their willingness to buy; Technical readiness is low, and purchase intention is reduced. Enterprises use digital technology to innovate and produce new products or services, and consumers with high technical readiness hold a positive attitude towards digital technology and have a strong willingness to purchase and use new products or services; Consumers with low technical readiness have a negative attitude towards digital technology, and have a weak willingness to purchase and use new products or services produced by enterprises using digital technology. 


\section{4 conclusion}

The purpose of this paper is to study how consumers' attitude towards digital technology affects their willingness to buy or use new products or services produced by digital technology. It is relatively new to look at digital technology from the perspective of consumers, and there are countless ways to further study it in the future. We reviews and summarizes the definition and connotation of digital technology, digital innovation, technical readiness and purchase intention. After reviewing the connotation of digital technology and digital innovation, it is concluded that digital technology is a necessary condition for digital innovation. Further explore the influence of consumers' technical readiness on purchase intention under the background of enterprise digital innovation. Studies have shown that consumers with high technological readiness hold an optimistic and innovative attitude towards digital technology, and are therefore willing to accept and try new products or services generated by brand applications of digital technology, and their willingness to buy is enhanced; and technological readiness consumers with low levels of suspicion and distrust of digital technology and low driving beliefs will reduce their willingness to buy new products and services produced by brands using digital technology. In a word, although digital innovation can bring benefits to enterprises by means of digital technology, consumers' different attitudes towards digital technology will further improve or reduce their intention to buy or use new products or services. Consumers have different technical readiness, different attitudes towards digital technology, and different willingness to buy new products and services produced by digital technology.

\section{Suggestion}

In the digital age, while enterprises use digital technology to carry out digital innovation, they need to observe consumers' attitudes and views in order to make the digital transformation of enterprises more successful. Brands can be divided into two types, modern brands and traditional brands. The modern brand symbolizes vitality, the brand evolves and moves with the development of the times, the traditional brand symbolizes stability and the brand is static[25]. For traditional brands, the stable characteristics lead to low technical readiness of consumers to use digital technology in this enterprise, so digital technology should be used carefully for digital innovation and transformation; For modern brands, the characteristics of innovation and vitality make consumers highly prepared for the use of digital technology. Therefore, we suggest that traditional brands and enterprises should take into account consumers' attitudes towards the use of digital technology in their digital innovation and transformation. It is relatively new to look at digital technology from the perspective of consumers. We only study the influence of consumers' personal characteristics on enterprises' use of digital technology and their purchase intention, and we can further study it from the perspective of consumers' perception of the usefulness of digital technology, and there are countless ways to further study it in the future.

\section{References}

1. P. Mugge, H. Abbu, T. L. Michaelis, A. Kwiatkowski, G. Gudergan, Res. Technol. Manage 63, 2 (2020)

2. P.M. Bican, A. Brem, Sustainability 12, 13 (2020)

3. D.Tilson, K. Lyytinen, C. Sorensen, Inrorm. Syst. Res 21, 4 (2010)

4. P.C. Verhoefa, T. Broekhuizena, Y. Bartb, A. Bhattacharya, J.Q. Dong, N. Fabiana, M. Haenleinc, J. Bus. Res 122 (2019)

5. M.A. Berawi, N. Suwartha, M. Asvial, R. Harwahyu, M. Suryanegara, E. A. Setiawan, I. Surjandari, T. Y. M. Zagloel, I. J. Maknun, Int. J. Tecgnol. Manage 11, $6(2020)$

6. J. Hagberg, M. Sundstrom, N. Egels-Zandén, Int. J. retail. Distrib 44, 7 (2016)

7. Y. Yoo, MIS. QUART 34, 2 (2010)

8. P. Wang, MIS. QUART 45, 1 (2021)

9. E. Hadjielias, O. Dada, A. D. Cruz, S. Zekas, M. Christofi, G. Sakka, J. Bus. Res 122 (2021)

10. S. Nambisan, K. Lyytinen, A. Majchrzak, , M. Song, MIS. QUART 41, 1 (2017)

11. J. Cruz-Cárdenas, J. Guadalupe-Lanasa, C. RamosGalarza, A. Palacio-Fierro, J. Bus. Res 122 (2020)

12. A. Parasuraman, J. Serv. Res 2, 4 (2000)

13. S.K. Roy, M. Balaji, A. Quazi, M. Quaddus, J. Retail. Consum. Serv 42 (2018)

14. M.F. Chen, N.P. Lin, Internet. Res 28, 2 (2018)

15. J.D. Borrero, S.Y. Yousafzai, U. Javed, K.L. Page, Comput. Hum. Behav 30 (2014)

16. C.M. Chao, T.K. Yu, Online. Inform. Rev 43, 1 (2019)

17. Y. Wang, K.K.F. So, B.A. Sparks, J. Travel. Res 56, $5(2017)$

18. Y.W. Chang, J.H. Chen, J. Retail. Consum. Serv 58 (2020)

19. J.L. Aaker, J. Mark. Res 34, 3 (1993)

20. N. Spears, S.N. Singh, J. Current Issues \& Research in Advertising 26, 2 (2004)

21. G.M. Mullet, M.J. Karson, J. Mark. Res 22, 1 (1985)

22. S. Kim, M.A. Littrell, J. Travel. Res 38, 2 (1999)

23. Y.W. Ho, B. Merrilees, J. Prod. Brand. Manage 17, 6 (2008)

24. A. Poushneh, A.Z. Vasquez-Parraga, J. Consum. Mark 35, 6 (2018)

25. L. Cian, A. Krishna, R.S. Elder, J. Mark. Res 51, 2 (2014) 